\title{
PENGARUH LARI BOLAK-BALIK MENGGUNAKAN BEBAN KAKI DAN CIRCUIT TRAINING TERHADAP KEMAMPUAN DRIBBLING PADA PEMAIN FUTSAL JUGADOR ANDALAS FC
}

\author{
Oleh : \\ HENGKI SAPUTRA \\ PENJAS FKIP UNIB, e-mail: hengkisaputra09@gmail.com
}

\author{
Ari Sutisyana \\ Universitas Bengkulu \\ Defliyanto \\ Universitas Bengkulu
}

\begin{abstract}
Abstrak
Penelitian ini bertujuan untuk mengetahui pengaruh latihan lari bolak-balik menggunakan beban kaki dan circuit training terhadap kemampuan dribbling pada pemain futsal di secara ilmiah. Adapun rumusan masalah dalam penelitian ini adalah apakah ada pengaruh latihan lari bolak-balik menggunakan beban kaki dan circuit training terhadap peningkatan kemampuan dribbling pada pemain futsal Jugador Andalas fc Kota Bengkulu. Populasi dalam penelitian ini adalah 30 pemain futsal Jugador Andalas fc Kota Bengkulu. Penelitian ini dilaksanakan di GOR Kota Bengkulu dan Lapangan futsal SMP N 12 Kota Bengkulu. Metode penelitian yang digunakan adalah One Group Pretest - posttest Design, penelitian ini secara objektif atau apa adanya dengan sampel 30 pemain Jugador Andalas fc Kota Bengkulu. Analisis statistik yang digunakan dalam penelitian ini adalah Uji t. Adapun hasil analisis Uji t hasil perhitungan antara tes awal dan tes akhir terdapat pengaruh yang signifikan. Hasil perhitungan peningkatan dribbling menyatakan bahwa nilai $t_{\text {hitung }}=11,10<t_{\text {tabel }}=2,001$ dengan taraf $\alpha=0,05$ maka $H_{o}$ ditolak dan $H_{a}$ diterima artinya terdapat pengaruh yang signifikan latihan lari bolakbalik menggunakan beban kaki dan circuit training terhadap peningkatan kemampuan dribbling pemain futsal, sedangkan kontribusi latihan lari bolak-balik menggunakan beban kaki dan circuit training terhadap kemampuan dribbling yaitu $\mathrm{K}=r^{2} \times 100 \%=86,49 \%$ sedangkan Sehingga dapat disimpulkan bahwa adanya kontribusi antara latihan lari bolak-balik menggunakan beban kaki dan circuit training terhadap peningkatan kemampuan dribbling pada pemain futsal yaitu $86,49 \%$.
\end{abstract}

Kata Kunci : Latihan, Lari bolak-balik, Circuit training dan Dribbling.

\begin{abstract}
This research is aimed to find out the effect of shuttle run exercises use ankle weight and circuit training on increase dribbling capabilities of the futsal player of Jugador Andalas FC Bengkulu City in futsal games scientifically. The subjects of this research are player of Jugador Andalas
\end{abstract}


Bengkulu City. Population of this research was 30 player of Jugador Andalas Bengkulu City. This research was carried out by one group pretest-posttest design and was conducted in GOR Bengkulu City and in Junior High School number 12 Bengkulu City. Statistical analysis used in this research was $t$ test. Based on the results of $t$ test analysis, there was significant influence in calculation result between pre test and post test. The results of this research showed that $t_{\text {calculated }}=11,10<t_{\text {tabel }}=2,001$ with $\alpha$ rate $=0,05$ there fore $H_{o}$ was rejected and $H_{a}$ was accepted. It means there was the significant effect of $X$ (shuttle run exercises use ankle weight and circuit training) on $Y$ (dribbling and shooting capabilities) in futsal games, while the contribution of running shuttle run exercise using the foot load and circuit training to the ability dribbling ie $K=r^{2} \times 100 \%=86,49 \%$. So it can be concluded that the contribution between running shuttle run exercise using the foot load and circuit training to the dribbling ability abilities in futsal player is $86,49 \%$.

Keyword: exercises, shuttle run, circuit training and dribbling.

\section{PENDAHULUAN}

Olahraga merupakan hal yang sangat dekat dengan manusia kapan dan dimana saja berada. Sebab olahraga merupakan salah satu kebutuhan hidup yang harus dipenuhi oleh setiap manusia. Olahraga menempati salah satu kedudukan terpenting dalam kehidupan manusia. Dalam kehidupan modern sekarang ini manusia tidak bisa dipisahkan dari kegiatan olahraga baik sebagai salah satu pekerjaan khusus, sebagai tontonan, rekreasi, mata pencaharian, kesehatan maupun budaya. Salah satu cabang olahraga yang saat ini sangat diminati oleh seluruh lapisan masyarakat, terutama kaum muda adalah olahraga futsal. Hal ini disebabkan karena olahraga futsal hanya memerlukan peralatan yang sederhana serta mendatangkan kesenangan bagi yang bermain.

Olahraga futsal yang dimainkan oleh dua regu yang saling berlawanan ini dapat dimainkan oleh siapa saja, baik anak-anak, usia muda maupun tua. Futsal merupakan permainan yang unik karena merupakan gabungan antara permainan sepak bola dan bola basket. Futsal bukan permainan yang bersifat perseorangan akan tetapi merupakan permainan yang bersifat beregu. Tiap-tiap regu terdiri dari 5 orang, sehingga harus ada kerjasama antar pemain untuk menghasilkan kemenangan. Meskipun tim terdiri atas pemain yang memiliki keterampilan dan teknik yang baik tetapi tidak memiliki kemampuan kolektif antar pemain, maka tidak menjadi jaminan tim tersebut akan menjadi tim yang solid. Olahraga futsal dapat dimainkan di dalam ruangan maupun di luar ruangan dan tidak membutuhkan tempat yang sangat luas, sehingga olahraga futsal merupakan salah satu olahraga praktis.

Berdasarkan hasil pengamatan yang dilakukan pada tahun 2016 dalam turnamen liga nusantara regional Bengkulu. Ada 16 klub yang ikut berpartisipasi dalam event ini, salah satunya yaitu Jugador Andalas fc. Dalam turnamen ini Jugador Andalas fc telah mencapai babak semifinal, namun langkah menuju final pun terhenti karena klub Jugador Andalas kalah pada babak semifinal 
dengan skor 3-5. Kekalahan klub Jugador Andalas fc disebabkan oleh beberapa faktor, salah satu faktornya yaitu masih rendahnya kemampuan dribbling pada pemain.

Berdasarkan hasil pengamatan (observasi) yang penulis lakukan terlihat bahwa pemain futsal klub Jugador Andalas FC (JAFC) Kota Bengkulu ini kemampuan dribbling dalam bermain futsal masih rendah. Hal ini dapat dilihat pada saat pertandingan, dribbling pemain masih bisa di block oleh lawan dengan mudah. Hal ini dikarenakan kurangnya latihan-latihan yang terarah untuk meningkatkan kondisi fisik yang menyangkut teknik dribbling pada pemain. Karena kurangnya latihan yang terarah sehingga kemampuan duel pada saat satu lawan satu dengan lawan tidak maksimal.

Bertitik tolak dari uraian di atas, penulis tertarik melakukan penelitian guna melihat bagaimana pengaruh latihan bolakbalik menggunakan beban kaki dan circuit training terhadap peningkatan kemampuan dribbling pemain. Dengan adanya penelitian ini diharapkan bermanfaat bagi peningkatan pretasi pemain futsal Jugador Andalas FC (JAFC) Kota Bengkulu.

\section{METODE}

Jenis Penelitian

Penelitian ini merupakan penelitian kuantitatif dengan menggunakan metode eksperimen dimana penelitian ini mengenai hubungan sebab-akibat. Menurut (Suharsimi Arikunto, 2010: 9) berpendapat bahwa "metode penelitian eksperimen adalah suatu cara untuk mencari hubungan sebab akibat antara dua faktor yang sengaja ditimbulkan oleh peneliti dengan mengeliminasi atau mengurangi atau menyisihkan faktor-faktor lain yang mengganggu".
Desain Penelitian

Penelitian ini menggunakan desain penelitian One-Group Pretest-Posttest Design. Maka pada desain ini terdapat pretest, sebelum diberi perlakuan. Dengan demikian hasil perlakuan dapat diketahui lebih akurat, karena dapat membandingkan dengan keadaan sebelum diberi perlakuan. Desain ini dapat digambarkan seperti berikut (Harsono, 2006: 83).

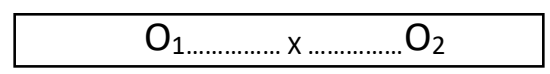

$\mathrm{O}_{1}=$ nilai pretest (sebelum diberi diklat)

$\mathrm{O}_{2}=$ nilai posttest (setelah diberi diklat)

Pengaruh diklat terhadap prestasi $=\left(\mathrm{O}_{2}-\mathrm{O}_{1}\right)$

Tempat Penelitian

Penelitian ini dilakukan di klub futsal Jugador Andalas fc Kota Bengkulu.

Waktu Penenlitian

Penelitian ini dilakukan selama 6 minggu terhitung dari dikeluarkannya surat izin meneliti hingga batas waktu yang ditentukan

Populasi

Populasi adalah wilayah yang terdiri atas : obyek/subyek yang mempunyai kualitas dan karakteristik tertentu yang ditetapkan oleh peneliti untuk dipelajari dan kemudian ditarik kesimpulannya, (Sugiyono, 2006: 89). Populasi dalam penelitian ini adalah pemain Jugador Andalas fc Kota Bengkulu sebanyak 30 orang.

Sampel

Sampel adalah bagian dari jumlah dan karakteristik yang dimiliki oleh populasi tersebut.Jadi sebagai sampel dalam penelitian ini adalah pemain futsal Jugador Andalas fc Kota Bengkulu dengan total sampel yang akan diambil berjumlah 30 orang dari populasi yang berjumlah 30 orang. Jadi sampel yang digunakan seluruh 
populasi yang ada, atau disebut juga dengan Total Sampling.

Untuk mendapatkan data dalam penelitian ini terlebih dahulu peneliti membuat beberapa langkah kerja yaitu :

1. Pelaksanaan Tes lari bolak-balik

a).Alat yang digunakan untuk tes pengukuran lari bolak-balik (shuttle run)

Perlengkapan : 1) Cone, 2) alat tulis, 3) stopwatch, 4) alat tulis, 5) ankle weight $1 \mathrm{~kg}$ Pelaksanaannya: 1).pemain berdiri di belakang garis dengan kaki depan tepat di atas garis start

2).Pada aba-aba "ya" pemain lari kedepan secepat mungkin ke garis lain, kemudian berputar dan kembali lagi ke garis start.

3).Setiap melakukan putaran kedua kaki harus melewati garis start dan garis finish.

4).Pemain harus melakukan kegiatan tersebut sebanyak 5 kali.

5).Diambil waktu tercepat.

2. Pelaksanaan circuit training

Pos 1 melakukan skipping selama 30 detik

Pos 2 melakukan sit up selama 30 detik

Pos 3 melakukan push up selama 30 detik

Pos 4 melakukan zig-zag selama 30 detik

Pos 5 melakukan lompat katak selama 30 detik

Pos 6 melakukan geser kesamping dengan kecepatan selama 30 detik

Pos 7 melakukan langkah panjang selama 30 detik

Pos 8 melakukan squat jump selama 30 detik Pos 9 melakukan sprint kedepan dan mundur selama 30 detik

Pos 10 melompati cone dengan satu kaki bergantian selama 30 detik

Pos 11 jogging mengelilingi area latihan selama 30 detik

Alat yang digunakan untuk tes Dribbling

Perlengkapan :

1. Cone

2. Meteran
3. Stopwatch

4. Peluit

5. Bola

6. Blangko dan alat tulis

Pelaksanaan :

1. peserta tes berdiri dibelakang garis start dengan sebuah bola di garis start.

2. Pada aba-aba "ya" peserta tes mendribble bola secepat mungkin melewati semua rintangan.

3. Pencatatan hasil diambil dari lama waktu tempuh dari start sampai finish dalam waktu persepuluh detik.

Teknik pengumpulan data

Dalam pengumpulan data peneliti menyiapkan sarana dan prasarana yang dibutuhkan dalam pelaksaaan tes terlebih dahulu. Kemudian peserta didik dibariskan untuk berdoa, dan presensi. Selanjutnya peserta didik melakukan pemanasan. Setelah itu peserta didik diberi perunjuk tentang pelaksanaan tes yang akan dilaksanakan.

Teknik pengumpulan data

Dalam penelitian ini mengunakan tes dribbling yang disusun oleh (Arsil, 2009: 129) dengan memodifikasi tekstur lapangan dan bola. Data yang akan dikumpulkan dalam penelitian ini yaitu data pretest dribbling melakukan tes menggiring bola sebelum sampel diberikan perlakuan.

Prinsip utama pelaksanaan tes menggirng bola utamanya adalah bola melewati pancang sebanyak 6 buah dengan jarak 1 meter sebanyak 2 kali percobaan dan waktu yang terbaik yang di pilih. Variabel yang di teliti dalam penelitian ini adalah latihan lari bolak-balik menggunakan beban kaki sebagai variabel bebas, sedangkan kemampuan menggiring bola (dribbling) sebagai variabel terikat. Teknik pengumpulan data dalam penelitian ini adalah dengan teknik tes. 
Teknik Analisis Data

Sebelum dilakukan pengujian hipotesis, maka perlu dilakukan uji prasyarat. Pengujian terhadap data hasil pengukuran yang berhubungan dengan hasil penelitian bertujuan untuk membantu dalam hal analisis agar menjadi lebih baik. Untuk itu dalam penelitian ini akan dihitung normalitas dan penghitungan homogenitas data.

Uji Prasyarat Analisis.

Penghitungan normalitas.

Penghitungan normalitas sampel adalah pengujian terhadap normal tidaknya sebuah data yang akan dianalisis. Untuk menghitung normalitas sebuah data bisa menggunakan cara membandingkan chikwadrat hitung dengan chi-kuadrat tabel. Berikut disajikan cara menghitung normalitas sebuah data:

\section{Rumus chi-kwadrat hitung}

$X^{2}{ }_{\text {hitung }}=\sum \frac{(f o-f e)^{2}}{f e}$
$f$

(Sugiyono, 2011: 172)

Keterangan:

$\mathrm{X}^{2}=$ Chi-Kwadrat

fo $\quad=$ Frekuensi yang diobservasi

$\mathrm{fe} \quad=$ Frekuensi yang diharapkan

Penghitungan Homogenitas.

Penghitungan homogenitas dimaksudkan untuk meyakinkan agar kelompok yang membentuk sampel berasal dari populasi yang sama. Untuk menghitung homogenitas dalam penelitian ini peneliti menggunakan cara membandingkan $F_{\text {hitung }}$ dengan $F_{\text {tabel. }}$ Berikut disajikan cara menghitung homogenitas sebuah data:

Rumus $F_{\text {hitung }}$

$F_{\text {hitung }}=$ Varians Terbesar
Varians Terecil

(Sugiyono, 2011: 199)

Pengujian Hipotesis.

Penelitian ini menggunakan metode eksperimen dengan desain penelitian yaitu Pretest-Posttest one Group Design. Analisis data dilakukan dua kali, yang pertama menguji kemampuan awal atau data pretest. Analisis yang ke dua adalah menguji hipotesis yang diajukan, yang di uji adalah kemampuan kelompok eksperimen yang telah diberikan latihan atau data posttest.

Pengujian hipotesis menggunakan uji-t satu arah. Pengujian dilakukan dengan $\alpha=0,05$ dan dengan derajat kebebasan $(\mathrm{dk})=\left(\mathrm{n}_{1}+\mathrm{n}_{2}\right.$ - 2). Secara manual, rumus uji - $t$ pihak kanan yang digunakan adalah sebagai berikut:

$$
\begin{aligned}
& t=\frac{\overline{x_{2}}-\overline{x_{1}}}{\mathrm{~s}_{\mathrm{t}}^{2} \sqrt{\left(\frac{1}{n_{1}}\right)+\left(\frac{1}{n_{2}}\right)}} \\
& \text { dengan } \\
& \mathrm{s}_{\mathrm{t}}^{2}=\frac{\left(\mathrm{n}_{1}-1\right) \mathrm{s}_{1}^{2}+\left(\mathrm{n}_{2}-1\right) \mathrm{s}_{2}^{2}}{\mathrm{n}_{1}+\mathrm{n}_{2}-2}
\end{aligned}
$$

(Sudjana, 1996: 239)

Keterangan :

$\overline{x_{1}}=$ nilai rata-rata hasil kemampuan

dribbling sebelum diberikan latihan

$\overline{x_{2}}=$ nilai rata-rata kemampuan dribbling

sesudah diberikan latihan

$\mathrm{n}_{1}=$ jumlah siswa pada kelas eksperimen

$\mathrm{n}_{2}=$ jumlah siswa pada kelas eksperimen

$\mathrm{s}_{\mathrm{t}}^{2}=$ variansi total (gabungan)

$\mathrm{s}_{1}^{2}=$ variansi kemampuan dribbling sebelum diberikan latihan

$\mathrm{s}_{2}^{2}=$ variansi kemampuan dribbling sesudah diberikan latihan

Kriteria pengujian : Ho ditolak jika thitung $>$ $t_{(1-\alpha)(\mathrm{dk})}$ dengan $\alpha=0,05$

Uji Korelasi

Koefisien korelasi ditentukan dengan rumus product moment dengan rumus sebagai berikut Sugiyono (2011:191): 


$$
r_{x y}=\frac{N \sum x y-\left(\sum x\right)\left(\sum y\right)}{\sqrt{\left(N \sum x^{2}-\left(\sum x\right)^{2}\left(N \sum y^{2}-\left(\sum y\right)^{2}\right)\right.}}
$$

Keterangan :

$r_{x y}=$ Angka indeks korelasi " $r$ " product moment

$$
\begin{array}{ll}
\mathrm{N} & =\text { Jumlah total } \\
\Sigma \mathrm{XY} & =\text { Jumlah hasil perkalian antara } \\
& \text { skor } \mathrm{X} \text { dan } \mathrm{Y} \\
\Sigma \mathrm{X} & =\text { Jumlah seluruh skor } \mathrm{X} \\
\Sigma \mathrm{Y} & =\text { Jumlah seluruh skor } \mathrm{Y}
\end{array}
$$

Uji Kontribusi

$R^{2} \times 100 \%$

Keterangan : $\mathrm{R}=$ koefisien korelasi

$\%=$ persentase

\section{HASIL DAN PEMBAHASAN}

\section{Hasil}

Berdasarkan hasil perhitungan dengan menggunakan Chi - Kuadrat dapat diketahui bahwa pre-test dan post-test berdistribusi normal.

Hasil dari pengujian normalitas pada data tes awal dan tes akhir dengan $n=30$ pada taraf signitifikasi $\alpha=0,05$ di peroleh $X^{2}$ tabel $=12,592$ yang lebih besar dari $X^{2}$ hitung sehingga dapat disimpulkan skor yang diperoleh dari data tes dribbling berdistribusi normal.

Uji Homogenitas Varians

Uji homogenitas dilakukan untuk mengetahui apakah semua data hasil penelitian merupakan data yang homogen atau tidak. Uji homogenitas dalam penelitian ini dilakukan menggunakaan uji $F$. Adapun hipotesis yang diuji adalah terdapat perbedaan antara data sebelum dan sesudah diberi perlakuan.

Kriteria pengujian yang digunakan dalam penelitian ini adalah data berdistribusi homogen jika nilai $f_{\text {hitung }}<f_{\text {tabel. }}$. Hasil uji homogenitas data penelitian menunjukan bahwa nilai $f_{\text {hitung }}=$
0,98 dan $<$ dari $f_{\text {tabel. }}=3,34$ sehingga data homogen.

Dari data pre-test dan post-test dapat diketahui varians sesudah dan sebelum sebagai berikut:Uji Hipotesis

Setelah melakukan uji prasyarat normalitas dan homogenitas, selanjutnya dilakukan uji hipotesis. Dimana pengujian ini dilakukan untuk mengetahui apakah ada pengaruh latihan lari bolak-balik menggunakan beban kaki dan circuit training terhadap kemampuan dribbling pada pemain futsal Jugador Andalas fc Kota Bengkulu. Untuk menguji hipotesis penelitian digunakan t-test dengan taraf signitifikasi $5 \%$. Rangkuman hasil perhitungan t-test sebagai berikut:

$$
F=\frac{\text { varians terbesar }}{\text { varians terkecil }}=\frac{5,94}{5,84}=0,98
$$

Diketahui bahwa antara pre-test dan post-test yang diajukan ( $\mathrm{Ha}$ ) dapat diterima, terjadi peningkatan yang signifikan pada peningkatan dribbling di dapat $t_{\text {hitung }}=11,10$ $\geq t_{\text {tabel }}=2,001$. Dalam uji kontribusi latihan lari bolak-balik menggunakan beban kaki dan circuit training sebesar $86,49 \%$ dan sebesar $13,51 \%$ dipengaruhi oleh variabel lain. Sehingga dapat disimpulkan bahwa latihan lari bolak-balik menggunakan beban kaki dan circuit training memberikan pengaruh yang signifikan terhadap kemampuan dribbling pada pemain futsal Jugador Andalas fc Kota Bengkulu.

\section{Pembahasan}

Penelitian ini berusaha untuk mengungkapkan apakah benar bahwa melalui latihan lari bolak-balik mengguakan beban kaki dan circuit training dapat meningkatkan kemampuan dribbling pada pemain futsal Jugador Andalas fc Kota Bengkulu. Kemampuan dribbling pemain Jugador Andalas Kota Bengkulu yang rendah membuat peneliti tertarik untuk meneliti ini 
karena permasalahan ini adalah suatu masalah yang sangat penting bagi pemain, karena dengan memliki kemampuan dribbling yang rendah mereka akan sering mendapatkan kekalahan karena sulit dalam melewati lawan. Mereka tidak mampu melakukan teknik dribbling dengan baik apalagi untuk melewati lawan kecendrungan malas belajar ketika tidak mempunyai kemampuan yang baik.

Sehingga melalui permasalahan inilah yang mendasari penelitian ini. Dan setelah dilaksanakan penelitian selama 1,5 bulan atau 6 minggu telah didapatkan hasil yang cukup memuaskan, yaitu adanya peningkatan kemampuan dribbling. Keberhasilan penelitian ini merupakan pembuktian dari pendapat para pakar, seperti Willmore dan Costill (1994) mengatakan bahwa subyek yang belum sama sekali terlatih menunjukkan peningkatan sebesar $20 \%$ atau lebih besar setelah mengikuti program latihan selama 6 minggu.

Berdasarkan hasil statistik hipotesis yang diajukan $(\mathrm{Ha})$ dapat diterima, terjadi peningkatan yang signifikakn pada peningkatan kemampuan dribbling $t_{\text {hitung }}=$ $11,10 \geq t_{\text {tabel }}=2,001 \quad$ sedangkan kontribusi latihan lari bolak-balik menggunakan beban kaki dan circuit training sebesar $86,49 \%$ dan sebesar $13,51 \%$ dipengaruhi oleh variabel lain. Sehingga dapat disimpulkan bahwa metode latihan lari bolak-balik menggunakan beban kaki dan circuit training memberikan pengaruh yang signifikan terhadap kemampuan dribbling pada pemain futsal Jugador Andalas fc Kota Bengkulu.

Berdasarkan perhitungan data hasil penelitian menunjukan bahwa secara keseluruhan tingkat kemampuan dribbling pemain yang mengikuti latihan futsal di klub Jugador Andalas fc Kota Bengkulu sebelum di beri perlakuan latihan lari bolakbalik menggunakan beban kaki dan circuit training terdapat 30 pemain yang melakukan tes awal mempunyai kategori kurang. Setelah diberi perlakuan 6 pemain masih dalam kategori sedang, 19 pemain dalam kategori baik dan 5 pemain dalam kategori baik sekali. Sehingga dapat disimpulkan bahwa tingkat kemampuan dribbling setelah diberi perlakuan meningkat.

Menurut (Harsono, 117: 1988) lebih penting dari intensitas latihan adalah mutu atau kualitas latihan yang diberikan pelatih kepada seorang atlet. Setiap latihan haruslah berisi dril-dril yang bermanfaat dan yang jelas arah serta tujuan latihannya. Atlet haruslah merasakan bahwa apa yang diberikan oleh pelatih adalah memang berguna baginya, dan bahwa hari itu dia telah lagi belajar atau mengalami sesuatu yang baru. Kalau bukan dibidang fisik, teknik atau taktik dalam segi mental dia telah mendapatkan pengalaman yang baru yang dirasakannya sebagai sesuatu yang penting dan berguna baginya.

Kemudian (Bompa,

1994:298) menyatakan bahwa latihan selama 8 minggu dengan bentuk interval training dapat meningkatkan kapasitas aerobik anak latih. Sehingga hal ini telah sesuai dengan apa yang telah peneliti kerjakan yaitu pemberian perlakuan selama 6 minggu dengan frekuensi latihan seminggu 3 kali dengan sesi atau pertemuan selama 60 sampai 120 menit dimulai dari awal minggu 60 menit sampai dengan akhir minggu 120 menit pertemuannya. Dan peningkatan ini terjadi juga karena dalam penerapan latihan telah menggunakan prinsip latihan, yaitu:

Prinisip Penambahan Beban Bertambah (Overload) 
Prinsip latihan paling mendasar adalah prinip overload, oleh karena tanpa penerapan prinsip tersebut tidak mungkin prestasi atlit akan meningkat. Penerapan sistem overload apabila atlet sudah merasa ringan dengan beban yang diberikan maka beban latihan meningkat. Dengan latihan beban bertambah penyesuaian fisiologis dalam tubuh yang mendorong meningkatkan kekuatan otot.

Prinsip Peningkatan Beban Terus Menerus

Otot yang menerima beban latihan berlebih kekuatannya akan bertambah. Apabila kekuatan bertambah maka program latihan berikutnya bila tidak ada penambahan beban maka tidak lagi dapat menambah kekuatan. Penambahan beban ini dilakukan sedikit demi sedikit pada set atau jumlah repitisi tertentu, otot belum merasa lelah.

Menurut Suharjana (2004: 69) circuit training merupakan bentuk latihan yang terdiri dari beberapa pos latihan yang dilakukan secara berurutan dari pos satu sampai pos terakhir. Jumlah pos antara 8-16 pos dengan istirahat dilakukan pada jeda antar pos satu dengan yang lainnya.Bentuk latihan biasanya disusun dalam lingkaran dan terdiri dari beberapa pos. Dengan sedikit kecerdikan dan kreatifitas pelatih akan dapat mendesain suatu sirkuit yang paling cocok untuk cabang olahraganya. "Circuit training" berarti beberapa kelompok olah raga atau pos yang berada di area dan harus diselesaikan dengan cepat. Tiap peserta harus menyelesaikan satu pos dahulu sebelum ke pos lainnya. Circuit training ialah suatu program latihan yang di ciptakan oleh R.E. Morgan and G.T. Anderson pada tahun 1953, dalam program latihan ini, terdapat beberapa stasiun kebugaran jasmani, seperti push up, sit up, dan lain-lain. Dalam program pelatihan ini biasanya digunakan peralatan mesin, peralatan hidrolik, beban tangan dan biasanya jarak tiap stasiun 15 detik sampai 3 menit untuk menjaga agar otot tidak kelelahan. Bentuk sederhana dari circuit training adalah lari keliling lapangan 10 kali, push up 10 kali, dan seterusnya.

Prinsip Pengaturan Suatu Latihan

Latihan berbeban hendaknya diatur sedemikian rupa sehingga kelompok otototot dulu yang dilatih sebelum otot yang lebih kecil. Hal ini dilakukan agar kelompok otot kecil tidak mengalami kelelahan lebih dahulu.

Prinsip Kekhususan Program Latihan

Semua program latihan harus berdasarkan adaptasi spesifik. Prinsip tersebut menyatakan bahwa hendaknya bersifat khusus sesuai dengan sasaran yang akan dicapai. Bila akan meningkatkan kekuatan maka program latihan harus memenuhi syarat untuk tujuan meningkatkan kekuatan.

Berdasarkan prinsip ini maka telah didapatkan hasil penelitian yang memuaskan dan telah membuktikan bahwa melalui prinsip latihan ini maka kemampuan dribbling pemain futsal Jugador Andalas fc Kota Bengkulu menjadi lebih baik atau meningkat secara signifikan. Dan demikian hasil penelitian yang telah peneliti laksanakan dengan hasil terdapat pengaruh latihan lari bolak-balik menggunakan beban kaki dan circuit training terhadap peningkatan kemampuan dribbling pada pemain futsal Jugador Andalas fc Kota Bengkulu setelah pemberian latihan selama 6 minggu.

\section{PENUTUP}

\section{Simpulan}

Berdasarkan analisis data yang dilakukan, maka diperoleh kesimpulan sebagai berikut: 
Dari hasil penelitian yang telah dilaksanakan selam enam minggu serta data dihitung melalui uji prasyarat dan uji $t$, bahwa sampel berdistribusi normal dan homogen. Hasil uji $t$ pada penelitian ini diperoleh $t_{\text {hitung }}=11,10 \geq t_{\text {tabel }}=2,001$ sehingga dapat disimpulkan bahwa latihan lari bolak-balik menggunkan beban kaki dan circuit training berpengaruh terhadap kemampuan dribbling pada pemain futsal Jugador Andalas fc Kota Bengkulu. Sedangkan bila dilihat dari perhitungan kontribusi diperoleh $\mathrm{K}=86,49 \%$ terhadap kemampuan dribbling. Dengan demikian latihan lari bolak-balik menggunakan beban kaki dan circuit training merupakan salah satu bentuk latihan yang dapat memberikan pengaruh yang signifikan terhadap kemampuan dribbling pada permainan futsal.

Berdasarkan hasil penelitian ini, terdapat pengaruh yang signifikan antara pengaruh latihan lari bolak-balik menggunakan beban kaki dan circuit training terhadap kemampuan dribbling pada pemin futsal Jugador Andalas fc Kota Bengkulu. Dengan demikian kedua variabel dapat dijadikan bahan pertimbangan dalam penyusunan program latihan olahraga futsal khusunya pada teknik dribbling yang didukung program latiham yang baik serta perlu mendapatkan perhatian khusus bagi pelatih, dan atlet sebagai usaha untuk meningkatkan kualitas teknik yang baik.

Dengan kemampuan menampilkan teknik dasar yang baik khusunya pada kemampuan dribbling diharapkan dapat meningkatkan prestasi dalam permainan futsal karena teknik yang baik seorang atlet dapat meimiliki rasa percaya diri dalam menampilkan permainan terbaiknya sehingga akan lebih mudah untuk menciptakan kemenangan tim dan pencapaian prestasi yang optimal.

\section{Saran}

Adapun saran-saran yang dapat dikemukan sesuai hasil penelitian, pembahasan dan kesimpulan yang telah diuraikan diatas adalah:

1. Bagi pelatih futsal agar dapat memberikan materi latihan yang tepat dan penyusunan program latihan khusunya untuk melatih kemampuan dasar guna meningkatkan kemampuan dribbling permainan futsal sehingga dapat meningkatkan dan mendukung dalam kemajuan olahraga futsal.

2. Bagi pemain diharapkan semangat luar biasa yang dimiliki para siswa dapat melaksakan program latihan hendaknya dapat diiringi dengan ketekunan dan kesungguhan sepaya dapat mendapatkan hasil yang optimal sesuai apa yang diharapkan.

3. Bagi penulis sendiri diharapkan dapat banyak memperoleh pendukung baik daru segi referensi literature ataupun informasi dari para senior dalam penelitian yang dilakukan.

\section{DAFTAR PUSTAKA}

Arikunto, Suharsimi. (2010). Prosedur Penelitian Suatu Pendekatan Praktik. Jakarta: PT Rineka Cipta.

Arsil. (2010). Evaluasi Pendidikan Jasmani dan Olahraga. Padang: Wineka Media.

Charlim, dkk.( 2011). Mengenal Lebih Jauh Tentang Futsal. Jakarta: Multi Kreasi Satudelapan.

Giriwijoyo, Santosa. (2012). Ilmu Faal Olahrga Fisiologi Olahraga. Bandung: PT Remaja Rosdakarya. 
Harsono, (1988). Coaching dan Aspek-aspek Psikologis Dalam Coaching. Jakarta: CV Tambak Kusuma.

Lhaksana, Justinus. (2011). Taktik dan Strategi Futsal Modern. Jakarta: Be Champion.

Lhaksana, Justinus., Ishak, H.Pardosi. (2008). Inspirasi dan Spirit Futsal. Jakarta: Raih Asa Sukses.

Mulyono, Muhammad Asriady. (2014). Buku Pintar Panduan Futsal. Jakarta: Niaga Swadaya.

Murhananto. (2006). Dasar-dasar Permainan Futsal. Jakarta: PT Kawah Pustaka.

Rohim, Abdul. (2008). Bermain Sepak Bola. Semarang: CV. Aneka Ilmu.

Sudjana, (1996). Metode Statistik. Bandung: Tarsito

Sugiyono. (2006). Metode Penelitian Kuantitatif Kualitatif dan $R \& D$. Bandung: Alfabeta.

Sugiyono. (2011). Metode Penelitian Kuantitatif Kualitatif dan $R \& D$. Bandung: Alfabeta.

Suharjana. (2004). Kebugaran Jasmani. FIK UNY. Yogyakarta

Sutrisno. (2007). Mempersiapkan Pemain Sepak Bola Berprestasi (1). Jakarta Barat: PT Musi Perkasa Utama.

Tangkudung, James. (2012). Kepelatihan Olahraga Pembinaan Prestasi Olahraga. Jakarta: Cerdas jaya ,(2016).Macam-macam

Metodologi Penelitian. Jakarta: Lensa Media Pustaka Indonesia
,(2018). Sport Psychometrics Dasar-dasar dan instrument Psikometri. Depok :Rajagrafindo persada

Yudiana, Yunyun. Dkk. (2008). Dasar-dasar Kepelatihan. Jakarta: Universtas Terbuka. 